NBER WORKING PAPER SERIES

\title{
GUARANTEEING DEFINED CONTRIBUTION PENSIONS: THE OPTION TO BUY-BACK A DEFINED BENEFIT PROMISE
}

\author{
Marie-Eve Lachance \\ Olivia S. Mitchell \\ Working Paper 8731 \\ http://www.nber.org/papers/w8731
NATIONAL BUREAU OF ECONOMIC RESEARCH
1050 Massachusetts Avenue
Cambridge, MA 02138
January 2002

The authors are grateful for research support from the Huebner Foundation, the Shannon Schieber Memorial Fund, the Society of Actuaries, and the Michigan Retirement Research Center (Lachance), the Pension Research Council (Mitchell), and the Department of Insurance and Risk Management (both authors) at the Wharton School. We are grateful for the comments provided by David Babbel, Jeremy Gold, Kent Smetters, and Kenneth Trager. The views expressed herein are those of the authors and not necessarily those of the National Bureau of Economic Research.

(C) 2002 by Marie-Eve Lachance and Olivia S. Mitchell. All rights reserved. Short sections of text, not to exceed two paragraphs, may be quoted without explicit permission provided that full credit, including (C) notice, is given to the source. 
Guaranteeing Defined Contribution Pensions:

The Option to Buy-Back a Defined Benefit Promise

Marie-Eve Lachance and Olivia S. Mitchell

NBER Working Paper No. 8731

January 2002

JEL No. G2, H

\begin{abstract}
After a long commitment to defined benefit (DB) pension plans for US public sector employees, many state legislatures have introduced defined contribution (DC) plans for their public employees. In this process, investment risk which was previously borne by state DB plans has now devolved to employees covered by the new DC plans. In light of this trend, some states have introduced a guarantee mechanism to help protect DC plan participants. One such guarantee takes the form of an option permitting DC plan participants to buy back their DB benefit for a price. This paper develops a theoretical framework to analyze the option design and illustrate how employee characteristics influencethe option's cost. We illustrate the potential magnitude of a buy-back option value enacted recently by the State of Florida for its public employees. If employees were to exercise the buy-back option optimally, the market value of this option could represent up to 100 percent of the DC contributions over the worklife.
\end{abstract}

Marie-Eve Lachance

Department of Insurance and Risk Management

Wharton School, Univ. of Pennsylvania

3641 Locust Walk, Philadelphia, PA 19104-6218

Email:malachan@wharton.upenn.edu

Olivia S. Mitchell (corresponding author)

Department of Insurance and Risk Management

Wharton School, Univ. of Pennsylvania

3641 Locust Walk, Philadelphia, PA 19104-6218

and NBER

Tel: 215-898-0424

Email: mitchelo@wharton.upenn.edu 


\section{Guaranteeing Defined Contribution Pensions: The Option to Buy Back a Defined Benefit Promise}

Defined contribution (DC) pension plans have been the primary engine of growth in the US private pension market over the last two decades. The public sector has traditionally been more tied to defined benefit (DB) pension plans, but recently several state legislatures have introduced DC plans for their public employees. A DC plan offers participants flexibility, portability, and investment portfolio choice, all of which can improve an employer's ability to attract and retain workers. ${ }^{1}$ But investment risk that had been assumed by the plan sponsor under the DB promise is transferred to the worker in a DC plan (Bodie, 1990).

Some public pension sponsors, therefore, have sought to provide a form of guarantee so employees will not be penalized by the conversion to a DC plan. This paper analyzes the potential costs to employers associated with a guarantee in which the employee covered by a DC plan is allowed to return to the DB plan, in exchange for a pre-specified price. We refer to this guarantee as the "buy-back" option, and we show that the potential costs involved with the provision of such a guarantee are easily misunderstood and can be quite large.

To evaluate the potential magnitude of the costs associated with a buy-back option, we explore two alternative designs recently developed by the State of Florida in implementing a statewide pension reform. Using numerical estimates, we show that the likely costs of Florida's buy-back option are substantial. If the employees were to exercise the buy-back option optimally, the market value of this option could represent up to $100 \%$ of the employees' total DC contributions. In Section I, we develop a framework to analyze the cost of the buy-back option. Section II describes the key features of Florida's reform while Section III outlines the 
methodology used to analyze this particular reform. Simulation results are provided in Section IV while Section V discusses these results and extensions of the research.

\section{The Defined Benefit Buy-Back Option}

A buy-back option is most easily understood in the context of a pension plan sponsor that is converting a DB plan into a DC plan. In its simplest form, a buy-back option allows an employee with a DC plan to return to the DB plan with full benefits at some time $t$, in exchange for a price $P(t)$. The buy-back price $P(t)$ may or may not be identical to $D C(t)$, the balance in the worker's DC account at that time. The option must be exercised by time $\mathbf{R}$, when the employee retires or leaves the plan due to termination. Throughout the paper, we will use bold letters to distinguish random variables from their realized value counterparts.

This option might seem similar to Margrabe's (1978) option to exchange one asset for another. In that context, the buy-back option would be interpreted as an option to exchange the future DC benefits for the future DB benefits plus a transaction adjustment of $D C(t)-P(t)$. A closer look, however, shows that the analogy with Margrabe's model fails due to the lack of a known market value for the assets exchanged in the buy-back option. ${ }^{2}$ Although the employee evaluates the decision of exercising the option at time $t$, the ultimate value of the assets exchanged, and consequently the profitability from exercising the option, will only be known at time $\mathbf{R}$.

To make further progress in understanding the value of buying-back into the DB plan, it is helpful to define the elements needed to analyze the buy-back option: the DB and DC benefits,

\footnotetext{
${ }^{1}$ For a discussion of pensions' impacts on employer and employee behavior see Mitchell (2000); challenges to the defined contribution pension environment are discussed in Mitchell and Schieber (1998).
} 
the buy-back price, the payoffs as a function of exercising the option, and the valuation criteria. Next we consider a two-step valuation method. In the first step, the optimal time of exercise for the buy-back option is defined concurrently with the payoff structure of the option. Second, using the employee's optimal buy-back time as an input, the value of the option can be determined.

\section{$\underline{\text { Defined Benefit and Defined Contribution Benefits }}$}

For ease of exposition, consider a new employee hired at the time of plan conversion $(t=0){ }^{3}$ Let $D B(t)$ represent the present value of the DB retirement annuity as of time $t$, computed using salary and service at that time, i.e., $D B(t)$ is the present value of the employee's "Accumulated Benefit Obligation" (ABO). Similarly, $D C(t)$ is the value of accumulated contributions in the DC plan, along with accrued interest, at time $t$. Let $\mathbf{i}$ represent the random investment return in the DC plan. The terminating employee may either receive his benefit payments as an annuity or a lump sum. While, in reality, the choice of benefit payment might affect a particular employee's relative value of $D B(t)$ and $D C(t)$ in the presence of heterogeneity and adverse selection, for now, we assume that the employee is indifferent between the two forms of payment; we return to this issue in Section V.

Figure 1 illustrates the projected expected value profiles for the DB and the DC plans as a function of $\mathbf{R}$. During the employee's early years of service, the value of the DC benefit exceeds the value of the DB benefit. As the employee nears retirement, however, the buy-back becomes more valuable due to the backloaded nature of the DB benefit formula.

\footnotetext{
2 The analogy also fails due to Margrabe's requirement that the two assets to be exchanged grow according to a lognormal distribution to obtain a closed form solution. Although each contribution in the DC plan grows lognormally, the sum of these contributions does not.
} 


\section{Figure 1. Expected Value of DB and DC Plan Benefits as a Function of Years of Service at Termination (R)}

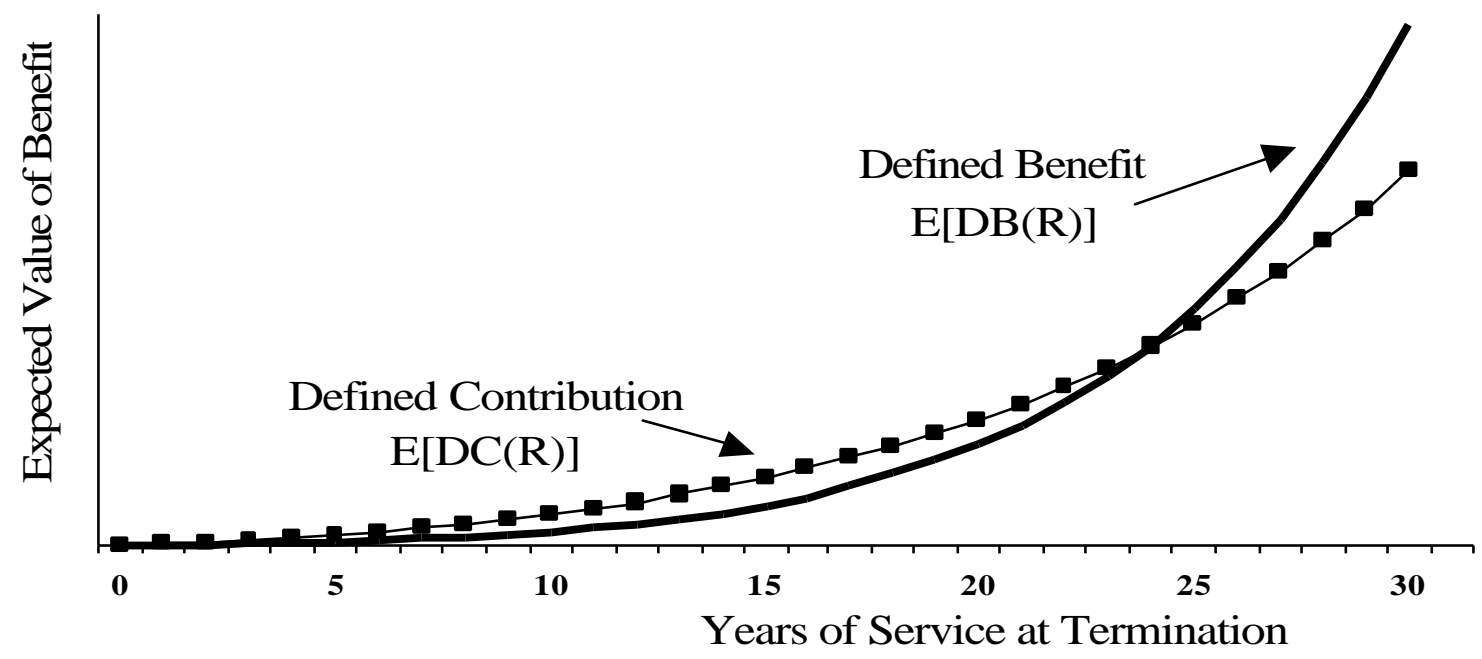

The Defined Benefit Buy-Back Price

Let $P(t)$ denote the buy-back price; specific cases are examined shortly. If an employee's DC account is insufficient to cover the buy-back price, he would have to use personal funds to cover the shortfall. If the employee's DC account exceeded $P(t)$ then he retains $D C(t)-P(t)$.

$\underline{\text { Payoffs }}$

The value of the benefits received by the employee at time $\mathbf{R}$ appears in Table 1, for the exercise and no-exercise case. In the no-exercise case, the payoff is simply $\mathbf{D C}(\mathbf{R})$. In the exercise case, the payoffs are a function of the time of exercise $t$. The employee receives the combination of $\mathbf{D B}(\mathbf{R})$ and the difference between the balance of his DC account and the DB buy-back price. Of course, this difference may be positive or negative, and it accrues with interest from time $t$ to $\mathbf{R}$. The employee does not know whether the option will be "in the money" when he exercises the option at time $t<\mathbf{R}$.

\footnotetext{
${ }^{3}$ Below we mention the case where an existing employee has previously accrued benefits at the time of conversion.
} 
Table 1. Value of Benefits at time $\mathbf{R}$ as a Function of Time of Exercise $(t)$

\begin{tabular}{ccl}
\hline & Exercise & No Exercise \\
\hline Value of Benefit & $\mathbf{D B}(\mathbf{R})+[D C(t)-P(t)](1+\mathbf{i})^{\mathbf{R}-t}$ & $\mathbf{D C}(\mathbf{R})$ \\
\hline
\end{tabular}

\section{$\underline{\text { Valuation Criteria }}$}

Because the pension offerings embody payoffs with random components, it is necessary to model how their value must be adjusted for risk. To assess how the employer could value the plan cost, it is useful to adopt the risk-neutral valuation technique based on no-arbitrage arguments derived from Cox, Ingersoll, and Ross (1985) and applied by Hull (1997). The approach discounts projected payoffs at the risk-free rate, subject to an adjustment in the drifts of each of the random processes determining the value of these payoffs. For traded securities, the resulting risk-adjusted drift corresponds to the risk-free rate. The operator $\hat{E}$ represents expectations taken with these risk-adjusted probabilities.

A different technique is adopted for the employee, since he may be unable to carry out a given no-arbitrage strategy. The employee is assumed to select whether and when to exercise the option by maximizing expected utility conditional on the information set available at the time of the decision.

\section{Employee's Optimal Time of Exercise}

The employee's optimal buy-back time is denoted by $\tau$, which is determined according to two criteria. The first requires that the employee's expected utility from exercising the option at time $t$ is higher than his expected utility from not exercising it. The second requires that the employee cannot foresee another exercise time $t^{*}>t$ at which the exercise of the buy-back 
option produces a higher expected utility. Hence, $\tau$ can be obtained with the following equations: ${ }^{4}$

$$
\begin{aligned}
& \tau=\min \left\{t \leq \mathbf{R}: \quad U_{t}(\mathbf{B B}(t))>U_{t}(\mathbf{D C}) \text { and } U_{t}(\mathbf{B B}(t))>U_{t}\left(\mathbf{B B}\left(t^{*}\right)\right), \quad \forall t^{*}>t\right\} \\
& \text { where, }
\end{aligned}
$$

$$
U_{t}\left(\mathbf{B B}\left(t^{*}\right)\right)=E\left[u\left(\mathbf{D B}(\mathbf{R})+\left[\mathbf{D C}\left(t^{*}\right)-\mathbf{P}\left(t^{*}\right)\right](1+\mathbf{i})^{\mathbf{R}-t^{*}}\right) \mid F_{t}\right\rfloor
$$

and,

$$
U_{t}(\mathbf{D C})=E\left[u(\mathbf{D C}(\mathbf{R})) \mid F_{t}\right]
$$

Specific utility functions are discussed in Section 3. To compute the cost of the option, it is useful to define an indicator variable $e(\mathbf{R})$, which takes a value of 1 when the option is exercised.

\section{$\underline{\text { Employer Costs }}$}

The employer's cost of offering the buy-back option is defined as the increase in the discounted value of all pension payments made to (or received from) an employee, on top of the DC plan. The notation can be adapted slightly to recognize that in the DC plan, the employer cost is the sum of the DC plan contributions made on behalf of the employee. Ofcourse, this is not equivalent to the employee's DC account value at any given moment, due to the variable nature of most returns. The term $\mathbf{D C}^{\mathrm{er}}(\mathbf{R})$ is used to represent employer contributions when the employee spends $\mathbf{R}$ years in the DC plan. Using the operator $P V(\cdot)$ to represent the discounted value of the payments made, the employee's expected cost of the buy-back option at the inception of the DC plan can be expressed as:

\footnotetext{
${ }^{4}$ Rather than assuming that this model actually represents all employees' behavior, the criteria may be interpreted as an upper bound for the value of the option.

${ }^{5}$ The probability space is defined by $(\Omega, \mathfrak{I}, P)$ where $\mathfrak{I}$ is the standard Brownian motion filtration.
} 


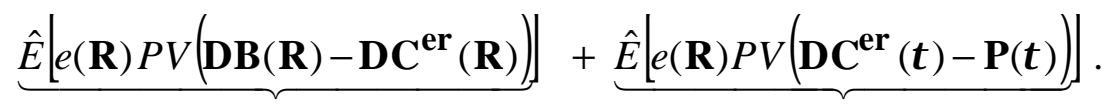

Employer gain/loss due to difference between DB and DC benefits when employee transfers from DC to DB plan
Difference between the employer past DC contributi ons and the

DB buy -back price

Equation (4) has two components that clarify the factors influencing the cost of offering the option. The component on the left represents the cost of allowing an employee the opportunity to trade his DC for a DB benefit, given that he expects to be better off in the DB plan. Figure 1 clearly indicates that this component becomes valuable only as the employee nears retirement; hence it is costless for employees terminating employment early, but potentially quite valuable for the most senior employees. For this reason, the employer's cost of offering a buy-back option is inversely proportional to the plan's employee turnover rate. The lefthand component of equation (4) also shows that the option cost is higher, the more backloaded is the DB promise relative to the DC benefit accrual.

The right-hand component of equation (4) increases with the difference between the value of the DC account and the DB buy-back price. The employee is likely to exercise the option when this value is at a maximum and avoid exercise where this value is significantly negative.

\section{$\underline{\text { Impact of the Buy-Back Price on Employee Behavior }}$}

One might wonder what would happen if, instead of charging a buy-back price, the employee were permitted to exchange the balance of his DC account for the DB benefit stream. In this case, an employee would wait until retirement to make his buy-back decision. At that time, he would receive the maximum of the DC or the DB benefit. Such a design would introduce moral hazard, since the employee could increase the value of the option by electing 
riskier investments in his DC plan. ${ }^{6}$ One way to address this moral hazard issue would be to adopt a buy-back price structure that is correlated with the employee's DC account balance, but independent of the employee's investment decisions. For example, the buy-back price could be defined as $P(t)=D C^{\text {index }}(t)$, where $D C^{\text {index }}(t)$ is the DC account balance computed with an index fund's return, rather than the employee's actual investment return. The difference between a perfect guarantee and this new design would then be attributed to "basis risk" (Smetters, 2002).

\section{Florida's Public Pension Reform Plan}

In what follows we show in more detail how the option values of interest can vary as a function of specific plan parameters and employee characteristics. To illustrate these issues in a real-world setting, we use the design and parameters of a buy-back plan recently adopted by the state of Florida as part of its statewide public pension reform. With over $\$ 100 \mathrm{~B}$ in assets and 600,000 public employees, the Florida Retirement System (FRS) is one of the largest public pension plans in the United States. Until recently, the state's retirement plan was a fairly typical DB pension; ${ }^{7}$ however, the Florida State legislature has adopted a new approach to retirement provision as of 2002. Both current and new employees are offered the alternative of participating in an entirely new DC plan. The old DB plan remains open to current workers and is also offered as an option to new hires that chose to join it. Figure 2 summarizes the key plan changes under the reform.

\footnotetext{
${ }^{6}$ Recent analyses of this point include Feldstein and Ranguelova (2000), Pennachi (1998) and Smetters (2000), the last of which shows that a minimum benefit guarantee induces investors to hold only risky assets (if capital markets are perfect) in their guaranteed DC accounts when those accounts are directly means-tested.

${ }^{7}$ For a recent review of public pension plan offerings see Mitchell and Hustead (2000).
} 
Figure 2. Plan Choices Offered Under the Florida Public Pension Reform

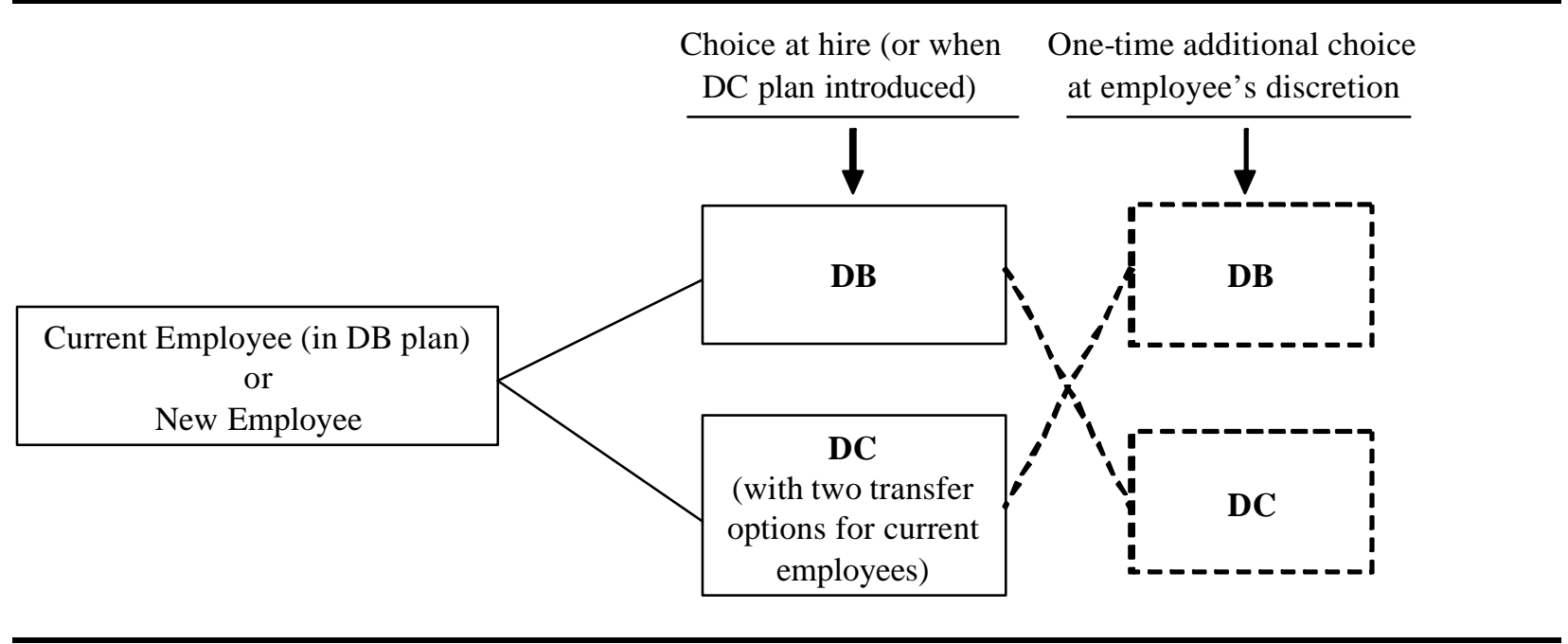

Existing employees who transfer to the DC plan must also decide how to handle their benefits accrued under the old DB plan. They may either retain a deferred benefit under the old $\mathrm{DB}$ plan, or they may transfer their $\mathrm{ABO}^{8}$ to the DC plan. Florida's pension reform bill (HB 2393) specifies how the ABO must be computed. It must use the worker's salary and service at the time of transfer, a discount rate and other actuarial assumptions specified by the Florida Retirement System Trust Fund at the time of the transfer, and an assumed retirement age, which is no younger than the employee's current age. ${ }^{9}$

For our purposes, the most interesting aspect of the Florida design is that, after the DC plan is launched, the public employee will be granted one subsequent chance to transfer to the other plan. ${ }^{10}$ If the employee transfers from the DC to the DB plan, he must pay a price defined

\footnotetext{
${ }^{8}$ The Accumu lated Benefit Obligation (ABO) represents the present value of the employee's benefit, where the current service and the current salaries are used to compute the benefit.

${ }^{9}$ For Regular class employees, the retirement age used for ABO calculations is the lesser of age 62 or the age when the employee would have completed 30 years of service (assuming he worked continuously).

${ }^{10}$ Much of the legislation and continuing comment on the HB 2393 Bill is available at www.fsba.state.fl.us and www.frs.state.fl.us. Sections of the Florida Statutes relevant to this analysis include s. 121.021, s. 121.3571, and s. 121.4501 .
} 
by the Florida statutes. This feature is conceptually equivalent to the buy-back option described

above. In the original reform bill (HB 2393), the buy-back price was defined as:

"the sum representing the contributions that would have been made to the DB plan for that employee and the actual return that would have been earned on those contributions had they been invested in the DB program."

A year later, before the plan was actually implemented, this was amended by Bill SB 2. As a result, the buy-back price has been changed, setting it according to the employee's ABO. The exact definition is as follows:

\begin{abstract}
"a sum representing the present value of that employee's accumulated benefit obligation immediately following the time of such movement, determined assuming that attained service equals the sum of service in the defined benefit program and service in the Public Employee Optional Retirement Program. Benefit commencement occurs on the first date the employee would become eligible for unreduced benefits, using the discount rate and other relevant actuarial assumptions that were used to value the FRS defined benefit plan liabilities in the most recent actuarial valuation. For any employee who, at the time of the second election, already maintains an accrued benefit amount in the defined benefit plan, the then present value of such accrued benefit shall be deemed part of the required transfer amount described in this subparagraph."
\end{abstract}

We refer to the se buy-back plans as Florida I and Florida II, respectively. The next section computes the value of these two different buy-back options.

\title{
III. Assessment Methodology
}

In this section we use numerical simulation to evaluate equation (4) for the Florida I and II cases. This provides estimates of the employer cost of providing the buyback option in the two contexts. 


\section{Heterogeneity of Agents}

As emphasized in Section I, the value of the buyback option is contingent on how long a given employee has been covered by the pension plan to date. To illustrate how this works, we model three types of employees, each of whom is assumed to join the DB plan at age 25 . At the time of the conversion, we assume that the three employee types have, respectively, 0 years of service, 10 years, or 20 years. For each of these employee types, we also devise estimates using low, medium, and high future termination rates. The average scenario is close to the pattern of actual termination rates for Florida public employees; ${ }^{11}$ the low rates are equal to half of the average, while the high rates are double average termination rates.

\section{$\underline{\text { The Pension Buy-Back Price }}$}

The FRS is comprised of several groups of employees, each having somewhat different benefit rules. The present analysis focuses on parameters for "regular class" workers, a category representing the vast majority of state employees (about 90\%). For these persons, the DB plan benefit formula equals $1.6 \%$ per year of service, times the average of the worker's last five annual salaries. The vesting period for the DB benefit is 6 years, in contrast to the DC plan with a more lenient 1-year vesting rule. For the valuation, this implies that new employees can buyback a DB benefit only after 6 years of service. ${ }^{12}$ The retirement benefit is indexed to a $3 \%$ nominal rate; as opposed to a real rate; all the remaining economic assumptions are therefore expressed in nominal terms. The normal retirement age (NRA) in the DB plan is the earlier of 62 years old or 30 years of service. In our simulations, employees enter the plan at 25 years old and hence would be able to retire at their NRA of age 55. Retirement payouts are assumed to be

\footnotetext{
${ }^{11}$ Average termination rates are derived using data on the numb er of employees terminating as a function of service in 1997-1998 (Trager et al., 2000). Termination rates are approximately 14\% for the first 4 years of service and 6\% thereafter. The number of employees per year of service is provided in FRS (1998).
} 
life annuities, which for our purposes are converted into lump sums using standard actuarial calculations and the relevant discount rate. Florida's mortality table has not been published, so we use a unisex version of the U.S. UP-94 mortality table.

The contribution rate established for the new Florida DC plan has been set at a uniform 9 percent of pay. For employees who accrued DB promises at the time of the conversion, one must ask whether they will be likely to leave their DB plan benefits with the old plan, or transfer their ABOs to the DC plan. Financially speaking, maintaining a deferred DB benefit makes sense to the employees because the current market discount rates are well below the 8 percent value that is used by Florida in their $\mathrm{ABO}$ calculation. On the other hand, employees may not realize that the $\mathrm{ABO}$ calculation does not represent a market value, so they might instead focus rather on the convenience of having the transfer and may also expect higher investment returns on the pool of funds deriving from the transfers. We illustrate our results only for the case where the employee transfers his $\mathrm{ABO}$ to the $\mathrm{DC}$ plan, since we believe it may be more plausible and the assumption does not affect our conclusions.

\section{$\underline{\text { Stochastic Processes and Risk-Neutral Valuation }}$}

To evaluate equations (1) and (4), it is necessary to define the various arguments of these formulas as a function of several stochastic processes, including the risk-free rate, investment returns in the DC and DB plans, salaries, and the contribution rate in the DB plan. The DC account balance calculation is a straightforward accumulation of contributions with returns. The DB computations use familiar techniques used by pension actuaries (Anderson, 1990). To simplify calculations, we assume that plan contributions, retirement payments, and the buy-back option exercise occur at the beginning of each year. These calculations take into account the

\footnotetext{
${ }^{12}$ Exercise before 6 years is not prohibited, but if employees do so, they will receive nothing if they terminate before being vested in the DB plan.
} 
specific provisions of the various Florida pension designs. For each of the five stochastic variables defined, we specify that each of these follows an Itô process of the form: $d \theta_{i} / \theta_{i}=\mu\left(\theta_{i}, t\right) d t+\sigma\left(\theta_{i}, t\right) d z$. (Estimated values of these stochastic process parameters are summarized in Appendix I, along with the corresponding risk-adjusted drifts for each variable, defined as $\left.\mu^{\prime}\left(\theta_{i}, t\right)=\mu\left(\theta_{i}, t\right)-\lambda \sigma\left(\theta_{i}, t\right).\right)$

The risk-neutral technique is useful because it eliminates arbitrariness in the modeling of the key variables in this problem, which are the risk-free rate and the DC plan investment return. For investment returns in the DB and DC plans, the adjusted drift is equal to the risk-free rate. For the risk-free rate parameters, Hull (1997) suggests that the current term structure leads directly to the process followed by interest rates in a risk-neutral world. Adjustments for variables unrelated to the price of a traded security are more difficult to determine. However, as Sherris (1995) notes when modeling salary growth in the pension context, the value of the option may be fairly insensitive to the drift adjustment assumption. Hence no adjustment is assumed for the salary and DB contribution rate processes.

\section{$\underline{\text { Specifying the Utility Function for Plan Participants }}$}

To model when plan participants might elect to buy back into the DB program, conditional on having first chosen the DC, it is necessary to specify a utility function. Following Mitchell et al. (1999), we specify a Constant Relative Risk Aversion (CRRA) utility function at retirement as follows:

$$
u\left(W_{r e t}+\mathbf{X}_{r e t}\right)= \begin{cases}\frac{\left(W_{r e t}+\mathbf{X}_{r e t}\right)^{1-\beta}-1}{1-\beta} & \text { for } \beta \neq \mathbf{1} \\ \ln \left(W_{r e t}+\mathbf{X}_{r e t}\right) & \text { for } \beta=\mathbf{1}\end{cases}
$$


where $\mathbf{X}_{r e t}$ is the value of accumulated pension assets at retirement, $W_{\text {ret }}$ represents other (nonpension) wealth, and $\beta$ reflects the assumed degree of relative risk aversion. Median household wealth at retirement (excluding pension assets) is assumed to be $\$ 240,000$ (in 2002 dollars), consistent with nationally representative data from the Health and Retirement Study (Moore and Mitchell, 2000).

To solve the plan participant's decision to buy back the DB promise, we substitute equation (5) into equation (1). Monte Carlo simulation is used to generate the optimal solution with $\beta$ set to 1 or 2 ; results below focus on $\beta=1$ since the findings are similar.

\section{Simulation Results}

Results are generated for the two buy-back option designs outlined for the Florida case by simulating equation (4) using a range of values for the model's five random variables. For each value of $\mathbf{R}$, we set $\mathbf{R}=R$ (where $R$ is between the participant's current age and the retirement age), evaluate the employer cost of offering the option using equation (4), weight the results by $P(\mathbf{R}=R)$, and sum them. The Monte Carlo simulations are repeated 10,000 times. For each draw, the variable representing the timing of the buy-back exercise, $\tau$, is obtained by evaluating equation (1) by Monte Carlo simulations as well.

\section{Employer Cost of Providing the Buy-Back Option}

The employer's cost of offering the buy-back option appears in Table 2, expressed as a percentage of the employee's salary to facilitate comparisons with the employer's $9 \%$ of pay contribution rate for the DC plan. Reported buy-back costs thus calculated reflect the cash flow required to finance offering this option over the worker's tenure at the firm, computed from his hire date. The computation requires that the option can only be exercised after the DC plan is 
instituted - for the new hire, after 0 years of service, and for existing employees, after 10 and 20 years of service.

Table 2. Employer Cost of the Buy-Back Option* (\% of total salary from hire to retirement)

Employment Termination Probability

\begin{tabular}{|c|c|c|c|c|c|c|}
\hline & \multicolumn{2}{|c|}{ Low } & \multicolumn{2}{|c|}{ Average } & \multicolumn{2}{|c|}{ High } \\
\hline & Florida I & Florida II & Florida I & Florida II & Florida I & Florida II \\
\hline $\begin{array}{l}25 \text { years old / } \\
0 \text { year service }\end{array}$ & $6.1 \%$ & $12.7 \%$ & $3.6 \%$ & $9.5 \%$ & $1.1 \%$ & $5.2 \%$ \\
\hline $\begin{array}{l}35 \text { years old / } \\
10 \text { years service }\end{array}$ & $10.2 \%$ & $10.2 \%$ & $7.6 \%$ & $7.6 \%$ & $3.9 \%$ & $3.9 \%$ \\
\hline $\begin{array}{l}45 \text { years old / } \\
20 \text { years service }\end{array}$ & $8.5 \%$ & $8.5 \%$ & $5.7 \%$ & $5.7 \%$ & $2.1 \%$ & $2.1 \%$ \\
\hline
\end{tabular}

* These costs represent maxima assuming optimal exercise of the option: actual costs could be lower. Results assume $\beta=1$.

The results in Table 2 indicate that, for average termination probabilities (consistent with actual rates in Florida public service), the additional employer cost associated with offering a buy-back option is substantial, from 4 to 10 percent of annual salary for the worker's entire tenure. This is significant compared to the 9 percent DC contribution rate. Recalling the decomposition of equation (4), the first component implied that employer cost would rise with employee seniority and fall with termination rates. This pattern is confirmed in Table 2:

compared to the middle column, a doubling in termination probabilities cuts the buy-back cost by about 4 percent of salary, and halving the termination probability increases buy-back costs by 3 percent of salary.

Thus far, our analysis has not emphasized what would happen to current employees who had a benefit in the DB plan when they transferred to the DC plan. Under the Florida reform rules the DB benefit would be "frozen" and computed with salaries in effect at the time of the conversion. If such an employee bought back into the DB plan, he would receive an additional 
benefit due to the recalculation of his past DB benefit using updated salaries. In Table 2, the employee with 10 years of service is the one most advantaged by this feature, which explains his higher costs. This cost is obviously higher than for the person with 0 years of service who does not benefit from recalculation. But the cost is also higher relative to the person with 20 years of service who is close to retirement and, therefore, does not face as many recalculation years before retirement.

The second component of the option valuation equation (4) predicted that option costs are affected by the difference between the employer's DC contributions and the DB buy-back price. Figure 3 below illustrates how this portion of the cost changes as a function of the buy-back time, for both Florida designs.

Figure 3. Expected Difference Between Employer Contributions and Buy-Back Price*, as a Function of Buy-Back Time $\tau$

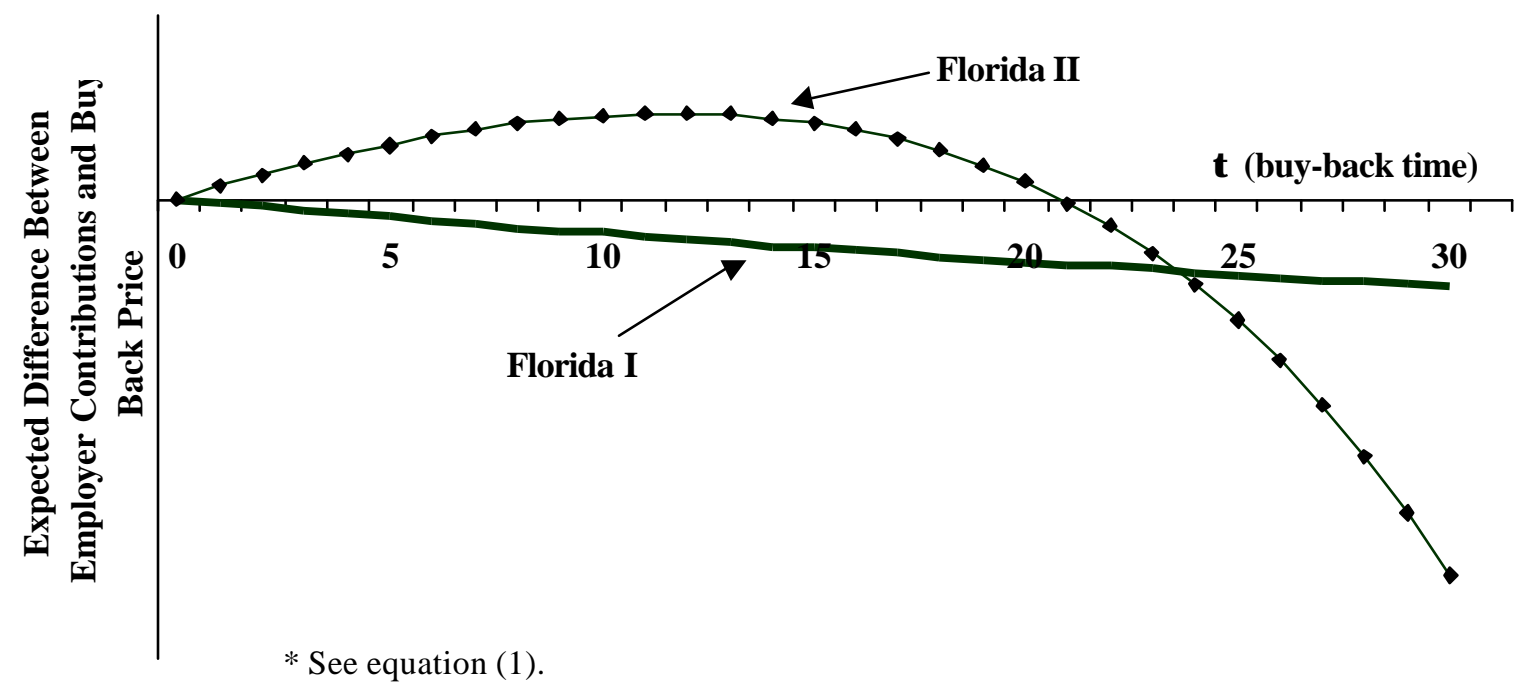

Under the Florida I plan, the buy-back price was equal to whatever the DB contribution rates actually were, plus realized rates of return on the DB plan investments. In this case, this second component of equation (4) always traces out a negative value in Figure 3, and the size of the gap rises with seniority. As a result, employees would be anticipated to always 
exercise their option as soon as they were permitted to do so. Senior employees would exercise the option immediately, while new hires would wait to be vested in the DB plan before exercising the option (after six years).

Under Florida II, the buy-back price corresponds to the employee's ABO. The evolution of the second component becomes somewhat more complex, starting out at zero, rising to attain a peak, and then becoming negative. The maximum cost is attained when the employee buys back after 12 years of service in the plan, and interestingly, it is quite large in magnitude. This explains why, for a new employee, the costs for Florida II as a percentage of salary are about $6 \%$ higher than for Florida I. For senior employees, the second component is close to zero when the DC plan is introduced and it declines thereafter. As a result, senior employees would be predicted to exercise the option immediately.

\section{$\underline{\text { Additional Remarks On Florida’s Buy-Back Guarantee }}$}

The modeling of the Florida guarantees outlined thus far abstracts from a few complexities. In practice, Florida's employees are permitted to choose either plan initially: when the DC plan is first instituted, and once again thereafter. As a consequence, employees who elect the DC plan initially will likely be those most advantaged by this choice. Therefore one might expect some selection: employees for whom the combination of the two components of equation (4) is high would be most likely to take the buy-back under the Florida II design. This is likely to exacerbate cost increases due to the reform.

It is interesting that the legislators' intent was probably to reduce the cost of the option by moving from the old to the new Florida plan. Most likely, policymakers worried about employees nearing retirement who could buy back the $\mathrm{DB}$ benefit for less than its $\mathrm{ABO}$ value under Florida I, prompting solvency problems. However this analysis shows that the second plan 
may be more costly than the first, since boosting the buy-back price relative to the DC account balance near retirement unexpectedly reduces this price earlier in the employee's career. Since the buy-back price is expected to be less than the DC account balance at the optimal buy-back time, employees can keep the difference. ${ }^{13}$

\section{Discussion and Conclusions}

When a plan sponsor moves from offering a defined benefit to a defined contribution pension plan, this may create a demand for a form of guarantee to protect plan participants against a sharp decline in retirement benefits. Our analysis indicates that offering employees an opportunity to buy back the DB benefit requires balancing participant protection and employer costs. In particular, adding a guarantee to a DC plan can result in employer costs greater than those associated with the original DB plan, instead of achieving cost savings. Under the buyback options considered here, employees continue to have access to the old DB plan benefits, for a price. Participants in these plans must therefore assess how the gap evolves between the DC account balance and the buy-back price evolves over time. If the buy-back price falls below the DC account balance at any time during an employee's career, he may receive a windfall.

Two buy-back designs have been explored by the State of Florida for its statewide public employee pension plan. The formula actually adopted permits participants to buy back their DB benefits in exchange for the value of their ABOs. Our results indicate that this design is potentially costly if the employees were to exercise the buy-back option optimally. In that case, the market value of the buy-back option could represent up to $100 \%$ of the DC contributions. The source of these costs can be illustrated in Figure 4, which depicts a newly hired worker with

\footnotetext{
${ }^{13}$ In s. 121.571 (4) of the Florida statutes, the FRS has specified the creation of a reserve corresponding to the gain from the original transfer of the employees from the DB to the DC plan. This reserve shall be used to offset the
} 
a starting salary of $\$ 30,000$. We illustrate the benefits the employee would get if he terminated employment either in the DC plan or in the DB plan. (DC plan benefits are projected with a rate of return of 8\%.) In addition, Figure 4 illustrates the return to a strategy of selecting the DC plan initially and then buying back into the DB plan after 16 years. ${ }^{14}$ This employee would obtain a bonus of about $\$ 50,000$ from the buy-back exercise, an amount that accumulates to $\$ 115,000$ by the time he reaches retirement. In this case, the mixed strategy of selecting the DC plan and then buying back the DB benefit after 16 years dominates the maximum of the DC and DB benefits at all times. It also provides an additional payment of $\$ 115,000$ at retirement.

Figure 4. Benefits of a DC Plan with a Buy-Back Option

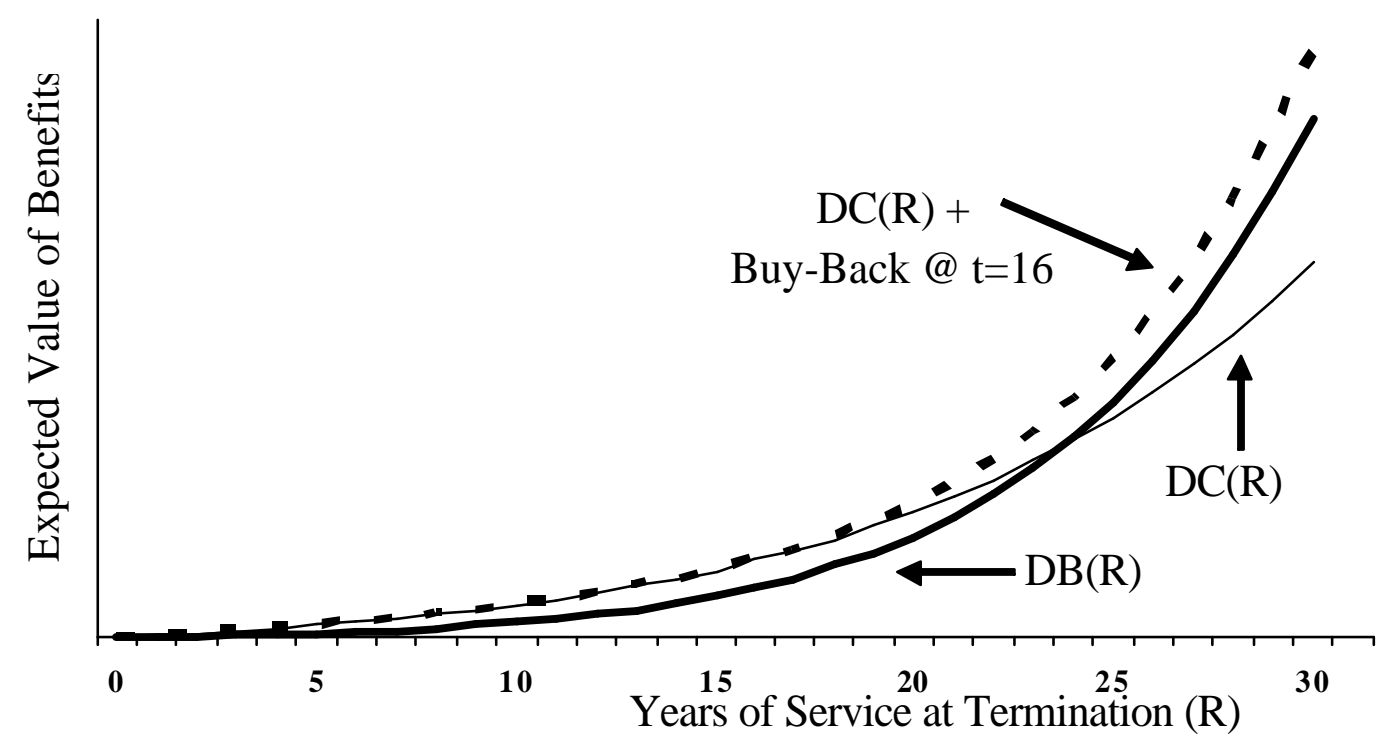

Our model could be extended in various ways. For instance, participants will have to become knowledgeable about when the various options are most valuable; if participants lack the necessary financial tools, their pension choices could deviate from those hypothesized here.

impact of employees exercising their second program election. However, it may not correspond to the actual costs of the buy-back option in practice. 
Alternative decision-making approaches might also lead to different employee choices than the ones used here. ${ }^{15}$ Some employees might face liquidity constraints preventing them from buying back their DB plan, if their DC account balance proves insufficient to cover the buy-back price. Retirees might have preferences how pension benefits are paid; for example, if a retiree is overannuitized or simply prefers liquidity, he might remain in the DC plan rather than exercise the buy-back option. Annuitization costs would also play a role: generally group annuities are less costly than individual purchases (Mitchell et al., 1999), making the DB plan relatively more appealing.

In addition, this simulation model assumes that employees follow an optimal buy-back strategy; however, employer costs could be much lower if employees did not pursue this tack. This prediction and model sensitivity could be investigated with evidence on Florida's state employee plan elections. The approach could also be adapted to assess other DC guarantee designs such as the Ohio State Teacher's Retirement System which recently offered its 401(a) participants a DC investment fund with a guaranteed annual return of at least 7.75 percent. Looking further afield, the Chilean government mandates a national DC pension plan while at the same time it guarantees an unfunded minimum retirement benefit (Zarita, 1994). This type of guarantee is subject to moral hazard, since workers will have an incentive to invest in risky assets so as to boost the value of the guarantee option (Pennacchi, 1999; Mitchell and Barreto, 1997). In the Florida case examined here, this moral hazard does not arise since the buy-back price relies only on DB plan parameters, rather than on DC account values.

\footnotetext{
${ }^{14}$ Note that the buy-back time is not necessarily optimal and is chosen simply for illustration purposes.

${ }^{15}$ The role of participant risk preferences in individual-account retirement plans is discussed in Geanakoplos et al. (1999).
} 


\section{References}

Anderson, A.W. 1990. Pension Mathematics for Actuaries (Second Edition), Actex Publications: Winstead, CT.

Bodie, Zvi. 1990. "Pension as Retirement Income Insurance." Journal of Economic Literature, 28 (March): 28-49.

Cox, John C., Jonathan E. Ingersoll Jr., Stephen A. Ross. 1985. “An Intertemporal General Equilibrium Model of Asset Prices.” Econometrica, Vol. 53(2): 363-384.

Feldstein, Martin and Elena Ranguelova. "Accumulated Pension Collars: A Market Approach to Reducing the Risk of Investment-Based Social Security Reform.” NBER Working Paper No. 7861, August 2000.

Florida Retirement System (FRS). 1998. Annual Report July 1, 1997- June 30, 1998. www.frs.state.fl.us.

Florida Retirement System (FRS). 1999. Annual Report July 1, 1998- June 30, 1999. www.frs.state.fl.us.

Florida Statutes. Chapter 121. www.leg.state.fl.us.

Florida Statutes. HB 2393 Bill. www.leg.state.fl.us.

Florida Statutes. SB 2 Bill. www.leg.state.fl.us.

Florida House of Representatives, Committee on General Appropriations. 2000. Final Analysis HB 2393 Bill. www.leg.state.fl.us.

Geanakoplos, John, Olivia S. Mitchell, and Stephen Zeldes. 1999. “Social Security Money's Worth.” In Prospects for Social Security Reform. Eds. O.S. Mitchell, R. Myers, and H. Young. Pension Research Council. Philadelphia, PA: University of Pennsylvania Press: 79-151.

Hull, John C. 1997. Options, Futures, and Other Derivatives. Third Edition. Upper Saddle River, NJ: Prentice Hall.

Margrabe, William. 1978. "The Value of an Option to Exchange One Asset for Another". Journal of Finance, 33(1) March: 177-186.

Mitchell, Olivia S. 2000. "Developments in Pensions". Handbook of Insurance. Ed. Georges Dionne. Kluwer Academic Publishers, Boston, 2000: 873-899.

Mitchell, Olivia S. and Flavio Barreto. 1997. "After Chile, What? Second-Round Social Security Reforms in Latin America". Revista de Analisis Economico, 12(2) November: 3-36. 
Moore, James and Olivia S. Mitchell. 2000. "Projected Retirement Wealth and Saving Adequacy". In Forecasting Retirement Needs and Retirement Wealth. Eds. O.S. Mitchell, B. Hammond, and A. Rappaport. Pension Research Council. Philadelphia, PA: University of Pennsylvania Press: 68-94.

Mitchell, Olivia S. and Sylvester Schieber, Eds. 1998. Living with Defined Contribution Pensions, Pension Research Council. Philadelphia, PA: University of Pennsylvania Press.

Mitchell, Olivia S., James M. Poterba, Mark J. Warshawsky, Jeffrey R. Brown. 1999. "New Evidence on the Money's Worth of Individual Annuities." American Economic Review. 89(5): 1299-1318.

Pennacchi, George G. 1999. "The Value of Guarantees on Pension Fund Returns." Journal of Risk and Insurance 66 (2): 219-237.

Sherris, Michael. 1995. "The Valuation of Option Features in Retirement Benefits." Journal of Risk and Insurance. 62(3): 509-535.

Smetters, Kent. Forthcoming. "The Design and Cost of Pension Guarantees." In Public Policies and Private Pensions. Eds. William Gale, John Shoven, and Mark Warshawsky. The Brookings Institution: Washington, DC.

Smetters, Kent. 2002. "Controlling the Cost of Minimum Benefit Guarantees in Public Pension Conversions." Pension Economics and Finance Journal, Forthcoming.

Trager, Kenneth, James Francis, and Kevin SigRist. 2000. "Florida's Public Pension Reform Debate: A Discussion of the Issues and Estimates of the Option Costs." In Pensions for the Public Sector. Eds. Olivia S. Mitchell and Edwin Hustead. Pension Research Council. Philadelphia, PA: University of Pennsylvania Press.

Zarita, Salvador. 1994. "Minimum Pension Insurance in the Chilean Pension System." Revisita de Análisis Económico. 9(1): 105-126. 


\section{Appendix I Stochastic Processes and Formulas for Value and Cost}

Our model has a total of five random variables, each following an Itô process of the form $d \theta_{i} / \theta_{i}=\mu\left(\theta_{i}, t\right) d t+\sigma\left(\theta_{i}, t\right) d z$. See Table A1 below gives the definition of each of the variables as well as their parameters estimates. We also define $\mu^{\prime}\left(\theta_{i}, t\right)=\mu\left(\theta_{i}, t\right)-\lambda \sigma\left(\theta_{i}, t\right)$ as the drift for the risk-adjusted processes. Justification for model choices and their parameter values is given below.

Table A1: Parametric Form and Parameters Estimates (All Variables Nominal)

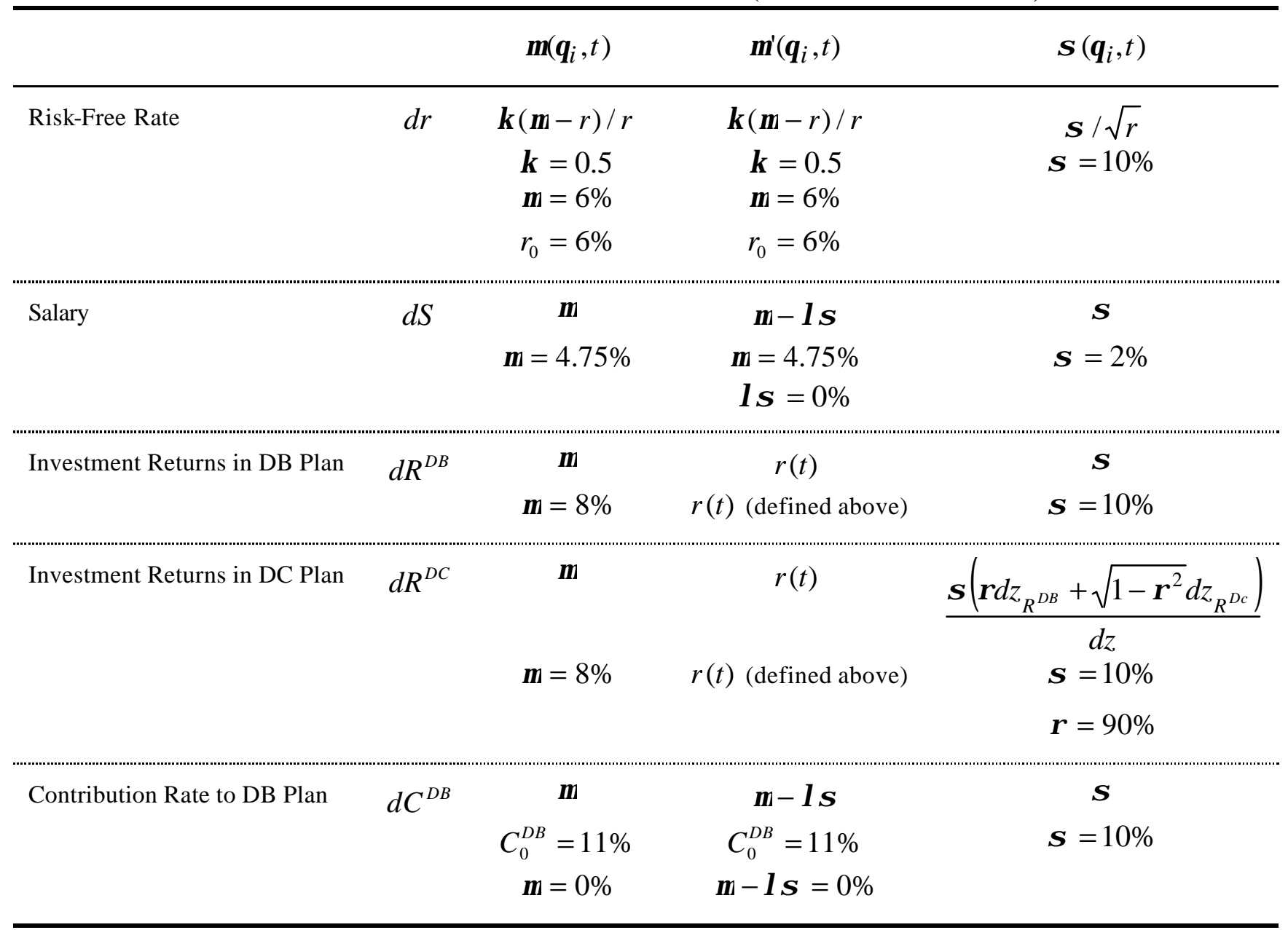

According to Hull (1997), the current term structure leads directly to the process followed by interest rates in the risk-neutral world. As of August 2000, the nominal and real yield curves were approximately flat with respective yields of $6 \%$ and $4 \%$, producing an expected inflation estimate of $2 \%$. In the special case of a flat yield curve, the difference between the various yield curve models narrows considerably. In that context, we can ignore the usual critique regarding the ability of Cox-Ingersoll-Ross to model short-rates and choose it as our yield curve model. The parameters $r_{0}$ and $\mu$ are chosen to match the current yield curve while $\kappa$ and $\sigma$ are estimated using historical data on T-Bills. 
For the salary drift, we add the inflation assumption (2\%) to the productivity $(1.5 \%)$ and average merit (1.25\%) assumptions as described in Trager et al. (2000) and the FRS (1999). The volatility parameter is estimated from historical inflation data. Inflation volatility ranges from $1 \%$ to $4 \%$ and a parameter of $2 \%$ is chosen to reflect the relatively low volatility in the most recent period. We set the market premium of risk to zero since Sherris (1995) showed that in a similar problem, the value of the option was not very sensitive to that assumption.

The drift for the rate of return in the DB plan was chosen to match the return assumption of $8 \%$ used by Florida in its state pension plan actuarial valuation. The risk-adjusted drift is simply the risk-free rate since we are dealing with the price of a traded security. The volatility assumption is estimated at $10 \%$, using historical returns during the postwar period and Florida's investment policy. We use the same assumptions for the DC investment returns. The nuance is that we add a parameter $\rho$ representing the correlation between the DC and DB investment returns. We set $\rho$ to be $90 \%$ since the returns in both plans should be closely but not perfectly correlated.

Finally, the contribution rate in the DB plan is the most difficult process to model since it represents the result of a complex combination of accounting, actuarial, and economic variables. Contrary to the DC counterpart, the DB contribution rate is variable rather than fixed over time. Hence a volatility parameter is required; to estimate it, we use the historical volatility of the contribution rate in the Florida DB plan which is $10 \%$. Determining the drift of the process is more complex. The DB plan contribution rate is currently about $9 \%$ and it is anticipated that this rate will rise after the reform, based on adverse selection that will be introduced by the optional DC plan. Employees remaining in the DB plan will likely be a relatively more expensive group than the original plan population. The simulations assume that after the conversion, the contribution rate will increase at $11 \%$ and follow a random walk thereafter. We have no particular view on the adjustment for the drift and hence it is set at zero; this should not strongly influence results. 